\title{
When structural violences create a context that facilitates sexual assault and intimate partner violence against street-involved young women ${ }^{\underline{t}}$
} \author{
Charlotte Gagnon ${ }^{\mathrm{d}}$, Vanessa Couturier ${ }^{\mathrm{e}}$, Pénélope Couturier ${ }^{\mathrm{a}}$

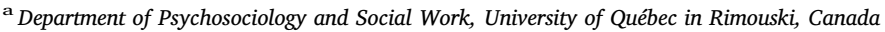 \\ ${ }^{\mathrm{b}}$ School of Social Work, University of Montreal, Canada \\ ${ }^{\mathrm{c}}$ School of Social Work, Laval University, Canada \\ ${ }^{\mathrm{d}}$ University of Montreal, Canada \\ e School of Social Work, University of Ottawa, Canada
}

Catherine Flynn ${ }^{\mathrm{a}, *}$, Dominique Damant ${ }^{\mathrm{b}}$, Simon Lapierre ${ }^{\mathrm{e}}$, Geneviève Lessard ${ }^{\mathrm{c}}$,

\section{A R T I C L E I N F O}

\section{Keywords:}

Violence against women

Street-involved youth

Structural violence

Social exclusion

Social control

Intimate partner violence

Sexual assault

\begin{abstract}
A B S T R A C T
This article presents findings from a participatory action research project conducted with a group of seven streetinvolved young women in the urban area of Quebec City (Canada). The objective of this research was to explore their experiences of homelessness through the lens of structural violence. Structural violence is the process through which social inequalities are produced. The data gathered through five focus groups revealed the presence of two gendered patterns of structural violence: social exclusion and social control. These two processes reinforce each other in a cycle. Indeed, the participants' strategies to overcome social exclusion and to fulfill their basic needs made them vulnerable to social control. In turn, social control had increased their financial difficulties and their fear of exclusion. These two processes of structural violence had also created contexts that facilitate sexual victimization and intimate partner violence.
\end{abstract}

\section{Introduction}

In the last two decades, there has been an increased interest in the experiences of street-involved youth. Several studies have framed these young people as an "at risk" population (Boivin, Roy, Haley, \& du Fort, 2005; Feng et al., 2013; Ferguson, 2009; Gomez, Thompson, \& Barczyk, 2010; Kidd, Karabanow, Hughes, \& Frederick, 2013; Mayock, Corr, \& O'Sullivan, 2013) or have considered homelessness as a deviance associated with criminal activities (Welch, Roberts-Lewis, \& Parker, 2009; Young, 2009). Although problems experienced by street-involved young women are widely documented, few studies have analyzed these problems with them, through the lens of structural violence.

This article presents findings from a participatory action research (PAR) that was conducted with a group of seven street-involved young women in the urban area of Quebec City (Canada). The objective of this research was 1) to explore their experiences of homelessness and their strategies through the lens of structural violence, and 2) to engage participants in social actions to overcome structural violence. While this article is focused on results associated with the first main goal of this study, social actions conducted by participants and an analysis of this
PAR process have been published in another article (Flynn, Damant, \& Lessard, 2015). This paper illustrates how the experiences of the participants are marked by processes of structural violence (social exclusion and social control) which have decreased the quality of their life conditions and safety. These processes overlap, working together to create a context where sexual assault, harassment and intimate partner violence are most probable to happen.

Street-involved young women: an "at risk" population

While it is difficult to precisely define the term street - involved youth, it accounts for varying degrees of homelessness and a wide range of behaviors and attitudes associated with street culture (Elliott, 2013). Young women appear to be the most vulnerable subgroup present on the street (Ensign \& Panke, 2002). Previous research suggests that young women's entry into street life or delinquency is associated with abuse and violence within their families (Belknap \& Holsinger, 1998; Medrano, Desmond, Zule, \& Hatch, 1999; Wingert, Higgitt, \& Ristock, 2005). For this reason, they would also be more at risk of living in fear, to experience anxiety or depression (Nehls \& Sallmann, 2005), and to

\footnotetext{
The authors wish to acknowledge the participation of Robbie, Abby, Tracy, Sandy, Debra, Kara, and Rory throughout the research process.

* Corresponding author.

E-mail address: catherine_flynn@uqar.ca (C. Flynn).
} 
have symptoms of post-traumatic stress disorder (Tyler \& Melander, 2009). Violence experienced in childhood could also lead to incidences of suicide attempts at a rate that is more prevalent among street-involved young women than their male counterparts (Hadland et al., 2012; Kidd \& Carroll, 2007).

Homeless young women are more vulnerable than homeless young men to experience different forms of violence, such as sexual assault (Ensign \& Panke, 2002; Rew \& ML Fitzgerald, 2001; Tyler, Hoyt, Whitbeck, \& Cauce, 2001), psychological violence, sexual harassment and police brutality (Dhillon, 2011). These women may consume drugs or alcohol (Chen, Tyler, Whitbeck, \& Hoyt, 2004), which could also be seen as a consequence of sexual victimization (Ferguson, 2009). Drug or alcohol addiction is also associated with prostitution as $20 \%$ of young women living in the street have been forced to offer sexual services in exchange for money, drugs or shelter (PHAC, 2006). While some authors have been interested in street-involved young women as an "at risk" population that needs to be protected, others have denounced a vast corpus of studies focusing on their delinquency (Bellot, Sylvestre, \& St-Jacques, 2013; Campbell \& Eid, 2009). Both homelessness and criminal behaviors are associated with violence and family conflict experienced by young women during childhood (Arnold et al., 2002; Belknap \& Holsinger, 1998; Dhillon, 2011; Loper, 1999; McCabe, Lansing, Garland, \& Hough, 2002; Medrano et al., 1999). While family factors and interpersonal violence experienced in the street are well known, there is a lot to understand about how institutions could reinforce violence and homelessness among street-involved young women. For example, few authors have revealed how these women face structural barriers which reduce their chances of success in various spheres of social activities (Oliver, 2013) such as education (Acoca, 1998), labour market, and housing (Dhillon, 2011). Even though they are recognized as a vulnerable population, street-involved young women could also be excluded from health care and social services (Dhillon, 2011). Studies presented in this section reveal the necessity to address the structural dimensions of homelessness through a genderspecific approach.

\section{What about their strategies?}

Scientific literature reveals that street-involved young women's survival strategies are influenced by gender stereotypes, since underground criminal and street economy appear to be dominated by young men (O'Grady \& Gaetz, 2004; Shannon et al., 2008; Walls \& Bell, 2011). Women are more likely to practice survival sex work in order to have a place to stay (Chettiar, Shannon, Wood, Zhang, \& Kerr, 2010; Shannon et al., 2008; Tyler et al., 2001; Walls \& Bell, 2011). Even if sexism, poverty and racism are considered as social factors associated with delinquent behavior among young women and adolescent girls, including street-involved youth (Bill, 1998; Slater, Guthrie, \& Boyd, 2001), some authors (Stephen, 2000; Welch et al., 2009) argue that it is important to address the various structural factors that support youth homelessness.

Therefore, this study focuses on the experiences of street-involved young women through the lens of structural violence.

\section{Structural violence}

This study was designed in accordance with an intersectional approach which suggests that the research be focused on social transformation, furthering knowledge about women who are marginalized (Bilge, 2015; Hancock, 2007; Collins, 2002). The concept of structural violence appeared as an opportunity to translate intersectionality through an empirical approach because of its multilevel analysis (Flynn, Damant, Bernard, \& Lessard, 2016). Structural violence is often associated with different international social movements of the 1950s and 1960s, such as the liberation theology in Latin America (Gutiérrez, 1973). Since its first operationalization (Galtung, 1969), this concept has often been criticized (Barnett, 2008; Parsons, 2007) and refined (Farmer et al., 2004; Ho, 2007; James et al., 2003). Authors that have studied the concept agree on presenting structural violence as a process that underlies social inequalities and produces suffering (Farmer et al., 2004) or the inability to fulfill basic needs (Ho, 2007).

In this study, we draw upon the work conducted by Scheper-Hughes and Bourgois (2004), who suggest that structural violence is a dynamic process between actors and structures, which are organized around three dimensions: symbolic domination, institutional violence and everyday violence. Symbolic domination is based on Bourdieu's (1980) work, as a system of (re)production of beliefs, representations and symbols holding hierarchies in place. Our results on symbolic domination show that the different kinds of violence faced by the participants, either in their everyday life or at an institutional level, are the product of prejudices and social representations towards street-involved women. Our definition of institutional violence is based on Foucault and refers to the violence perpetrated by the state and various institutions such as health and social services (Foucault, 1975; Lagraula-Fabre, 2005). Finally, ScheperHughes (2004) defines everyday violence as daily individual experiences of violent practices in interpersonal interactions that normalize brutality within micro-communities. Thus, structural violence occurs in an interactive and iterative process. In addition to these dimensions, it is also important to pay attention to the different power relations and social positionality that have shaped the participants' experiences.

\section{Methodology}

This study was part of a broader pan-Canadian research project on structural violence towards marginalized youth in Canada (12-25 years) entitled Voices against violence and led by Helen Bermen (2011-2017 CIHR). Participatory action research (PAR) methodology was selected as a feminist methodology to mobilize street-involved young women with the aim of using their experiential knowledge for social transformation and self-determination. Several researchers have used PAR with youth (Flicker et al., 2008; Harper \& Carver, 1999; MacDonald et al., 2011; McHugh \& Kowalski, 2011; McIntyre, 2000; Ozer, Ritterman, \& Wanis, 2010). Considering youth as experts of their own lives allows them to become producers of knowledge and equally supports them in becoming agents of social transformation (Flicker et al., 2008). In this case, social networks and visual materials were used as strategies for social change. When conducted with street youth, PAR revealed that these young people can be enrolled in promising projects that are meaningful and transformative for their communities (Bellot, Rivard, \& Greissler, 2010: p. 190; Petrucka et al., 2014: p. 54; Wingert et al., 2005).

\section{Research process}

The PAR was conducted over the course of a little more than a year. The data collection process took place during five meetings between June and October 2013. These meetings were held at irregular intervals because of the summer holidays and the fact that the participants were travelling in and out of the city. Some meetings took place in the apartment of one of the participants, which was located in a housing cooperative for single teenage mothers. Other meetings were held at a community organization for street-involved youth in Quebec City. The meetings were held in a setting where the participants discussed over a shared meal. Participants expressed their point of views and shared their different experiences of homelessness as well as the strategies they used to answer to their needs or to end their situation of homelessness, such as strategies of help-seeking. They discussed the circumstances that led them to street life, as well as their experiences of violence that occurred within that context and while they tried to escape it. The collected data was also discussed and analyzed with the participants during five subsequent focus groups between November 2013 and 
March 2014. These meetings helped participants identify common issues and organize collective social actions (Flynn et al., 2015) to fight against structural violence. Even if participants were involved at all stages of the research, including the transfer of knowledge, they didn't express interest to be a part of a scientific publication process nor a theoretical discussion. However, they were comfortable enough to participate in academic activities of knowledge mobilization, using their real names and disclosing their identities. These activities seemed to be more meaningful to them and closer to their aspirations for participation in the project. When they were invited to collaborate on the article, they declined and reiterated their confidence in the main researcher's ability to relate their stories with accuracy.

\section{Participants}

The participants were recruited among participants of a program offered at a community organization for street-involved youth in Quebec City. All were between 18 and 23 years old, had experienced episodes of homelessness and still lived in precarious life conditions (difficulty in fulfilling their basic needs or finding a safe and stable place to live). They lived mainly on social assistance programs, such as welfare, employment benefits or educational support programs. The majority of the participants used drugs or alcohol on a regular basis. Three of them identified themselves as sexual minorities and one had full custody of her small child.

\section{Data analysis}

The five data collection meetings were recorded and transcribed by four participants. These transcripts were subsequently analyzed with thematic content analysis according to the method of L'Écuyer (1990), using NVivo10 software. Research material was first coded within the three dimensions of the structural violence framework. Data was then recoded in different subcategories, specifically "Prejudice towards street-involved young women" (subcategory of symbolic domination), "Violence perpetrated by police officers" (institutional violence), or "Intimate partner violence and sexual assault" (everyday violence). Results of this study were discussed and validated with participants. Participants were also presenters in several knowledge-transfer activities such as scientific conferences, academic seminars, and workshops with staff from local community organizations.

\section{Results}

The data highlighted several prejudices towards street-involved young women, characterizing them as a group who are marginalized. These prejudices are part of a symbolic domination as they reflect different power relations. This characterization could explain or justify certain interactions between participants and institutions such as the child protective system, the network of health and social services, etc. From these interactions, two distinct embodied patterns had emerged: social exclusion and social control. In some cases, the participants' narratives presented experiences of institutional violence that contributed in weakening their social safety net and amplifying their social exclusion. In other cases, they denounced the regulation and control imposed by authorities. This section presents the results of the participants' experiences through the lens of the three dimensions of structural violence.

\section{Social exclusion}

Social exclusion is defined as a process of breaking social links in different spheres of social life (Paugam, 1996). It operates through policies and organizational practices, leading to deprivation (Grenier \& Guberman, 2009). For the participants, social exclusion manifests itself in different interactions that weaken the links between them and basic social institutions, like family, child protective services, the job market, housing, health care, and social services. Participants criticized the child protective system and discussed their different reasons for dropping out of the educational system. They also mentioned the requirements of the labour market as well as the ones of housing owners which disqualified them from the outset. Furthermore, they denounced the bureaucracy and selectivity of social assistance programs offered by various levels of government as well as the regulation of financial institutions and the organization of food banks. These experiences of institutional violence are seen as the result of symbolic domination processes related to gender, social class, sexual orientation and age, positioning our participants as a marginalized group.

For example, at the very first meeting, participants talked about class prejudice and the social stigma related to poverty, specifically towards recipients of social welfare. Analysis of the participants' discourse stressed that the persistence and recurrence of pejorative discourse towards those whom we call "BS" have tainted their interactions with other citizens, landlords, employers or health professionals. It is important to notice that BS, in province of Quebec, is an insulting and derogatory term for recipients of social welfare. The negative messages relayed about "BS" in the media are widely accepted by the population. It crystalizes people on social welfare as undesirable and dependent on state support. People who are called "BS" are also categorized as too lazy to get a job and to improve their living conditions.

"In this case, it is better to pay for us to go to school and try to get out of this $\mathrm{S}^{* * *}$ instead of paying for a big and dirty BS."

Kara, 21 years old

This quote demonstrates how participants refuse this label and to be seen as lazy, but it also shows that they might hold this prejudice towards others. They do not disconstruct this social representation but they reproduce it against people who seem to be less committed than they are in improving their lives. So, even if they hold prejudices towards social assistance recipients, they too take part of this symbolic violence. These examples of class prejudice about dependency and individuals on social assistance appear to be the product of a meritocratic and capitalist society where poverty is seen as an individual weakness rather than the result of structural processes (Valentine \& Harris, 2014). Although class prejudice seems to affect particular sub-groups, such as disabled people or immigrant populations (Valentine \& Harris, 2014) in different ways, a gendered analysis of class bias appears to be insufficiently documented within existing research.

Nonetheless, the discourse of the participants demonstrates the intersection between class prejudice and sexual orientation stigmas. The experiences of participants who identify as sexual minorities were shaped by a heteronormative vision of society. This concept was completely unknown by participants at the beginning of the research and was discussed in various meetings and analyzed during knowledgetransfer activities. Chambers (2007) defines heteronormativity as a system that constructs social categories in which heterosexuality is a desirable and "normal" reality, assuming that sex, gender and desire are perfectly linear and consistent with one another (see also Butler, 2006). Therefore, heteronormativity refers to a social world vision where cisgender males engage in heterosexual relationships with cisgender females. This contributes in maintaining hegemony through different social and everyday practices as it promotes the exclusion of non-heterosexual sexualities and gender identities that stretch beyond the feminine and masculine dichotomy (Bastien Charlebois, 2011). The participants' reflections towards heteronormativity during the PAR process created a new perspective on their own experiences, such as situations where they faced homophobia or in which their reality had been obscured or misunderstood by health and social service professionals, as we will see below.

Rupture with family and child protective system (CPS)

All participants had lived experiences of rupture with their families. 
Whether due to violence, abuse, conflict, neglect or economic difficulties, they associate these situations with their entry into street life. In addition, four of the seven participants were in foster care or in a foster family during their teenage years. Analysis revealed that the barriers they met in this setting contributed to the loss of their confidence in CPS and in social service agencies in general. Some participants vehemently denounced the mistreatment of children living in foster care or the sexual abuse of those living in foster families. This following quote, from a participant of the study, portrays how a traumatic experience in a foster family can greatly compromise self-esteem and belonging.

"There are some disgusting families ... Like, get threatened ... Worse, being raped... There has been more than one of the same... After that, try moving out [...] The first time you try to trust someone, you cry. Then, you learn to never do it again."

Sandy, 20 years old

Mistrust and a low opinion of foster care and foster families are strengthened by their lack of stability. While Sandy had 15 different social workers during her three years in foster care, Debra, who is Indigenous, lived in 13 foster families before being adopted by a nonIndigenous family at the age of 11 . Participants declared knowing many street-involved youth who have had similar experiences with CPS. Nevertheless, it is possible that this view may be biased, considering that young people who have experienced stable and peaceful trajectories are under-represented among street youth. The facts remains that the instable nature of CPS measures and its inaction in cases of abuse, as described by participants, are a manifestation of institutional violence. Feminist studies such as Dunkerley (2017) have suggested that CPS is an institution that reproduces class and racial inequalities. Debra's pathway in foster care appears similar to that of many other Indigenous children, since CPS as seen as a colonialist system that imposes a hegemonic representation of motherhood (Flynn \& Brassard, 2012; Kellington, 2000; Ordolis, 2007).

\section{Disqualification in the labour market}

During the year that this study was conducted, only one participant had lived with paid employment. Participants attributed their difficulties in getting a job to the level of skill requirements and their own physical appearance. Also, homelessness complicates procedures related to employment, insofar as applicants cannot offer a phone number or address. For this reason, it appeared impossible for some participants to find employment when they attempted to leave the street.

"How can you get a job? No education, no job, no experience, no job, piercings, no job, tattoos, no jobs. Dreadlocks, no job. No education, no experience, tattoos, piercings, weird hairstyle, NO JOB."

Robbie, 22 years old

To some extent, participants sometimes seemed to have internalized this disqualification. The various barriers they encountered in their job seeking dissuaded them, for fear of being judged because they were welfare recipients or had criminal records.

"It was difficult to get a job when I have got my criminal records... I could not say: Hey I was in the street, I stole to get food!!! [...] when you are on social welfare, it is difficult because they [employers] only see the dark side of social welfare recipients"

Kara, 21 years old

\section{Being refused for housing}

The participants' experiences are also characterized by struggles to access or to remain in healthy or safe housing. They explained that the functioning of the housing market has excluded them from the outset because they have either failed credit checks or couldn't even apply for one, having never had access to credit. Furthermore, they could not provide referrals. Without these documents, they have found it impossible to sign a lease. They also explained that physical appearances related to marginality lead to mistrust among landlords.

"When your clothes are all torn, they [landlords] will for sure not take you. They'll say that you won't be able to pay."

Kara, 21 years old

It is possible that distrust from the part of landlords, as well as the obligation to provide documentation may be understandable, considering that the participants had been evicted several times because of their inability to pay. They explained this by their difficulty in obtaining paid employment and by insufficient monthly allowances offered by government programs.

"With my cheque, once my apartment and all the accounts are paid, I have four dollars left in my bank account"

Abby, 20 years old

Both exclusion from the labour market and housing can be interpreted as a result of social profiling that focuses largely on their physical appearance as it is disruptive with normative femininity. While Deliovsky (2008) argue that patriarchy and racism frame a hegemonic vision of femininity and beauty, the participants' experiences show how this representation can also be imposed by a privileged class bias.

\section{Bureaucracy: feeling discouraged}

For the participants, the bureaucracy of social assistance offered by various levels of government, such as welfare, employment financial assistance or educational support programs, can be a manifestation of institutional violence. One participant explained that applications for social assistance require many documents that homeless people do not have.

"For welfare, they need several papers. But... How could I have that? Worse, if you do not have all of them in the same month you have to do it again from the beginning"

Sandy, 20 years old

The consequences of the bureaucracy associated with financial support programs have mainly arisen when participants attempted to put an end to their homelessness. This has demobilized some participants facing their efforts to end their street situation and maintained them for several months in a precarious situation. Two participants, who were at the age of 18 at the beginning of our study, discussed the difficulties they encountered when trying to obtain financial assistance as minors, at the age of 16 and 17. At that age, these women weren't in child protective services. They were however, street-involved, unemployed, out of school, without revenue and engaging in activities related to the milieu. Without being homeless per se, they lived in extreme poverty and had precarious living conditions.

Once they do get financial assistance, participants noted that access to their funds is complicated by the rules and regulations of financial institutions. Participants felt that they had significant financial problems at the end of the month. Furthermore, they could only have access to their allowance five working days (one week) after it was deposited into their bank accounts. The funds were held by the bank to ensure the validity of the cheque. Some had access to only $100 \$$ out of the entire amount, while others had no access to funds at all. These problems made paying the rent on the first of each month difficult, requiring negotiations with landlords. Recurring or chronic financial difficulties, or other factors such as owning a dog, can increase tensions with landlords. As such, participants could quickly find themselves in a situation of vulnerability and instability or even facing eviction.

Community organizations for homeless people: experiencing exclusion

Participants described situations where they had been excluded from last resort services. One example presented by the participants suggests that the image of the "bad girl" was reproduced by the workers of an emergency shelter. They refused to help this participant (who has 
dreadlocks, tattoos, piercing on her face) after her squat was destroyed by a fire. They argued that she had previously been rude with the staff. This raises the issue that some resources choose "good" clients or users.

"They told me that I was rude, so they did not want to take me. I wasn't rude. I did not want to tell them why I had a fight with my friends"

Robbie, 22 years old

During the research process, the group discussed how young, resistant women are misperceived and misunderstood. They felt that they had been labeled as "bad girls". Their oppositional behavior, such as resistance within a problematic family dynamic, was misinterpreted as delinquency. In a meta-analysis on how girls and young women are portrayed, Brown (2011) identifies three performances: the sad, the mad and the bad girl. The sad girl is disillusioned by men's misogyny while the mad girl translates her sadness through arts and music. The bad girl, associated with street-involved young women, is presented as an arrogant, strong, difficult and violent young woman. Brown (2011) criticizes the way in which the bad girl's anger is completely obscured and misunderstood and how the focus is turned towards their deviance and their inadequacy with femininity. This phenomenon raises the hypothesis that the participants' self-identification with the "bad girl" could be the result of a gendered symbolic domination.

Other participants encountered barriers in obtaining food assistance since it operates by place of residence. The service is difficult to obtain for those who regularly move or for people living off the street. Participants also explained that food service schedules are not suitable for people enrolled in rehabilitation programs, since they are only open during the day. This participant quips:

"I could not go to food banks because I was in school ... the food banks schedules are designed for "BS" people who don't do anything"

Abby, 20 years old

These comments suggest that participants are concerned that this service is designed strictly for people who match the stigma associated with people on welfare.

\section{Consultation in health institutions: between judgment and non-recognition}

The issue of violence experienced in health and social services was shared by participants, as they felt judged by the staff of health care institutions. For example, a participant sought help after taking amphetamines. She felt threatened by the nurse who didn't look after her once she had disclosed her drug use. In another situation, the participant felt she had experienced homophobia from a doctor. In addition to her physical appearance associated with marginality by her piercings and her hairstyle, she defined herself as a butch. She directly linked the poor attitude of the doctor to her physical appearance. This kind of behavior by caregivers may have subsequently compromised the security of the participants, since they claim that these experiences can dissuade them to seek help when they feel sick.

Furthermore, two participants experienced situations that made them feel uncomfortable because health professionals assumed they were in heterosexual relationships. One participant arrived at a clinic for nausea and was forced to take a pregnancy test, even though she claimed not to have had sex with a man. The other participant had to disclose her sexual orientation in front of a member of her family even though she was not ready to come out.

"It happened to me too... I was dating a girl it was like ... [...] I was at the clinic for the contraceptive pill ... [...] I was with a girl and I just wanted to know when I would be on my period... to be regular [...] I had to pass a pregnancy test because I had an active sex life ... [...] but I looked at my mother, at the doctor... I was embarrassed to tell her ... my mother did not know at that time"

Robbie, 22 years old
Participants identify this kind of homophobic behavior as a part of the social exclusion they face, a deterrent in seeking help from health and social services agencies.

Although all the participants engaged in this PAR process have been victims of one or multiple sexual assaults, some of them noted being poorly understood or discredited by health and social services. Their experiences of assault seem to also be ignored by awareness campaigns. These campaigns utilize a narrow representation of rape, generally perpetrated with brutality, by a man against a woman. One participant said she was raped twice by a woman, a reality rarely discussed and barely recognized.

"I was raped twice and each time it was by a woman [...] It hurts because you do not hear about it, it is not known, recognized"

Tracy, 18 years old

Another woman says that the understanding of rape as portrayed in awareness campaigns and in the general society does not address the issue of rape in dating relationships, or in a context where the victim does not try to resist. These examples portray how rape and the social responses towards rape are constructed through gendered scripts of sexual assault (Hayes \& Carpenter, 2013) As such, sexual violence can reinforce gendered scripts of powerlessness and femininity for women and conquest and masculinity for men (Hlavka, 2014).

In summary, this section presented different examples of institutional violence that have been part of a dynamic of social exclusion. The participants' experiences presented above show various breakpoints with child protection services, the labour market, housing, specialized resources for homeless people and health and social services as well as the State. These processes could appear to be the result of symbolic violent identification. Paugam (1996) argues that poverty is the ultimate manifestation of the process of exclusion. Grenier and Guberman (2009) also criticized that exclusion is too often understood as a consequence of poverty instead of the process that produces it. As shown in this section, each participant lived in conditions of extreme poverty with food and residential insecurity, as a result of numerous experiences of exclusion. This quote illustrates the pattern in which exclusion maintains them in a precarious situation:

"To get a job, you have to have gone to school, to go to school, you need a place to stay, to get a place to stay, you need money, to get money, you need a place to stay or to go to school, etc...."

Robbie, 22 years old

This process of exclusion combined with experiences of violence in their family led participants to become homeless during their adolescence and after they turn 18. To fulfill their needs, they have to use some illicit strategies such as non-declared work, survival sex work, robbery, panhandling and selling drugs which expose them to social control. A forthcoming article will describe how these strategies are also part of a gendered process, illustrating unequal power relations between young men and women involved in the street economy.

\section{Institutional violence - social control}

A second process of institutional violence that disciplines and punishes participants has been identified. These experiences can be associated to social control as defined by Foucault (1975). It refers to all practices that aim to constrain people to comply with social standards. Several participants argued that their different trajectories in child protective services and their interactions with law enforcement had placed them in situations where they experienced violence and coercion. They were very critical of the different practices used in foster care facilities and of the way police officers enforced municipal bylaws in an unfair manner. As seen previously, these processes could be interpreted as a product of a symbolic violent identification where participants were labeled as bad girls. This identification had occurred before their entry into street life, was pursued while they were living off 
the street and was then reinforced by some of their behaviors or physical appearances (tattoos, piercings, hairstyles). This labeling tainted their interactions in different settings, mainly with the child protective system and with police officers.

\section{Feeling "locked up" in foster care}

Four participants who had lived in foster care criticized the way in which young people are treated. They explained how young people can be placed in care for reasons other than delinquency. Behavior disorders in youth can also occur as a reaction to problematic or abusive situations present in the family (sexual abuse, violence, neglect, abandonment, etc.)

"Concerning the child protective system, youth go in care because their parents do not look after them. It's not their fault, most of time it's because of their parents. Then, they go to a safety unit, try to escape and become street-involved youth or runaways"

Kara, 21 years old

This quote illustrates participant's belief that the coercive climate in foster care leads teenagers to delinquency and to the street. They believe that the discrepancy between the needs of girls in care and the approach that treats them as "criminals", as if they were in youth detention centers, can exacerbate problems or encourage rebellion. This rebellion can lead them on a path of becoming street-involved because they are trying to escape a coercive climate.

"They all end up worse than when they entered. They're stuck with more delinquent girls and more restrictions than ever before. After, the girls want to revolt [...] They learned to see delinquency as a cool thing [...] They say "I'm sick of being locked up by people who work for the government!"

Robbie, 22 years old

Some participants reported incidences of psychological violence from the staff which lowered their self-esteem. According to some, this context where young women feel faced with injustice, while living in a mouse trap, makes opposition necessary for survival. Thus, it is possible to believe that different behaviors and the cases of runaways from care would reinforce the bad girl image (Brown, 2011) and crystallize them into this role.

\section{Social profiling}

While participants did not directly address the concept of social profiling, analysis reveals that some of them have been profiled. Social profiling is a form of discrimination based on physical appearance associated with poverty and marginality (Campbell \& Eid, 2009). Participants repeatedly denounced excessive control of their identity as well the number of citations issued by police officers. This leads them to believe that they were profiled because of their physical appearances (visible tattoos, piercings, torn clothes, etc.) and because of the places they frequent (places known as street-involved youth hangouts). The participants also expressed that the police hands out fines to street youth who jaywalk, panhandle or sleep in parks. Repression of sleeping in public spaces was strongly contested by one participant, considering that they are the safest places to sleep.

"Police officers and security guards always move you out if you are visible. You are at greater risk to have something go wrong [sexual assault] if you are hidden than if you're visible."

Robbie, 22 years old

In addition to the risks of being sexually assaulted, discipline by law enforcement can contribute to the criminalization of street-involved youth as well as an increase in their economic insecurity. One participant denounced the criminalization of homeless people and the vicious circle in which she was herself maintained. In addition, police control can increase over time, giving rise to harassment and brutality.

"About justice... I know it does not concern everybody here... But I had a lot of trouble, fines when you are on the street, you know... I got I-don't-know-how-many thousands of dollars in tickets... How am I supposed to be able to pay the bills? And you are there, begging... Where is the logic? I will have to beg to pay the tickets I got when I was begging?"[...] When they [the police] arrest you once, then they just give you more $s^{* * *}$. [...] if you're lying outside, they will wake you up, search you... They have already kicked me to wake me up."

Kara, 21 years old

This participant narrated a humiliating episode of police brutality during a second arrest following a theft in which she was involved. She didn't resist or argue with the police officers.

"Once, the police shook me up real good. They [police officers] grabbed me by the hair, were banging my face on the trunk of the car and kept giving me small blows between the butt cheeks with their baton."

Kara, 21 years old

For these participants, the humiliation they suffered during these episodes with the police only adds to the shame of having committed an offense and being in the street. Only one participant does not consider herself a victim of abusive control, harassment or brutality by police officers. She says they were always polite and respectful in their interventions with her. Other participants explained that it was probably because she did not have a physical appearance associated with marginality. Thus, it is possible to believe that she was not initially profiled.

This section has described how the participants were profiled and how their undesirable behaviors were controlled by several authorities. In this case, resistant behaviors were disciplined in child protective systems and participants were punished and controlled because they were profiled for their physical appearances. These practices could be justified by authorities' perceptions of street-involved youth such as discussed before.

\section{Everyday violence: sexual and intimate partner violence}

While previous sections have shown that symbolic domination and structural violence, as experienced by street-involved young women, are constructed by gender, social class, age and sexual orientation, these women also experience gender-based violence in their everyday lives. Their strategies to overcome social exclusion, to avoid social control and to fulfill their needs expose them to sexual assault and intimate partner violence.

\section{Sexual assault and soliciting for sex}

While objectification is part of many women's gendered experience, this study shows that the visibility of participants on the street and the misogyny of this space increase the possibility of being sexually assaulted. All participants reported at least one episode of sexual violence in the street or as a consequence of social exclusion or control. They described many situations where they were sexually assaulted by a street partner or a male passerby while trying to escape the control of the police force.

"I thought he was a good guy, we had fun, smoked joints together... Right when we were alone he started to touch himself and told me that I was turning him on. I told him I was not interested... to put his clothes on... I did not..."

Robbie, 22 years old 
While sleeping in a hidden place is unsafe for street-involved young women, it is just as unsafe to be taken in by friends or a male passerby.

"When you're on the street, there are always guys offering you a place to stay...to take a shower, but they will never let you go before you offer something in return..."

Abby, 20 years old

For participants, this is a kind of prostitution associated with survival sex work. Considering that prostitution is often associated with street life, all the participants, as describe previously, were frequently approached by men for sex. Participants revealed that their presence in the street as girls and women can be quickly associated with sex work. The participants advanced the idea that it's as if their presence, when sleeping in the streets, means that their body no longer belongs to them and can be touched and used for the pleasure of men.

"They [men] think that because you are there [sleeping on the street or in a park], they can ... [sexually assault you]"

Kara, 21 years old

In this context, it is possible to identify a symbolic domination process in which an erroneous representation of street-involved young women, as being more available to sexuality, more willing or ready to do anything to get drugs or money, is produced. This process could be associated with rape culture which occurs in a context where rape and sexual violence against women appear to be inevitable, even tolerated, through different practices or attitudes (Buchwald, Fletcher, \& Roth, 2005). The participants' experiences show that they have been specifically exposed to this culture as homeless women. Structural violence thus created a context where participants were likely to experience one or more experiences of sexual assault. All participants felt that they had been victims of sexual violence. Harassment, assault, and soliciting for sex appeared to be a very worrying element for all of them even if they have never sought for help to overcome the effects of these traumatic aggressions.

\section{Intimate partner violence}

All participants have been victims of intimate partner violence. In some cases, this violence can be linked to their unstable living conditions brought about by social exclusion. In other situations, intimate partner violence increases their difficulties and vulnerability. Several participants, either in a past or in a current relationship, have been victims of sexual violence or brutal episodes of physical violence that have produced serious injuries.

"I went to the hospital. I did not feel well... He threw me down the stairs"

Debra, 23 years old

It is also worth noting that intimate partner violence reported by participants often occurred during the context of a break-up.

"It happened once with my ex-boyfriend. He was possessive and I had just left him. He was really intense, like... I was trying to leave, but he locked the door, pushed me on the floor... He did not want me to go."

Abby, 20 years old

While Tyler, Melander, and Noel (2009) support bidirectionality of intimate partner violence among a population of street youth, the young women in this study affirm that they have never initiated the violence, although they had retaliated in some situations.

Although an intimate relationship with a young man could provide a relative feeling of safety in the street, participants also claimed that the violence inflicted by a partner had trivialized violence in general, making it difficult to recognize. This illustrates the complexity of the links between the three dimensions of structural violence. Intimate partner violence appears to be a real concern for the participants. The idea of having a male intimate partner is a strategy for them to prevent sexual assault on the street, and helps them overcome exclusion (Côté, 2013). This also indicates how notions of protection are associated with masculinity for the participants.

\section{Discussion: social exclusion and social control as gendered processes of structural violence}

The aim of this article was to present the experiences of seven streetinvolved young women through the lens of structural violence. It identified four manifestations of symbolic domination that constructs how this particular population is perceived. It also emerged that experiences of institutional violence as reported by the participants were organized around two processes: social exclusion and social control. In turn, these two processes create contexts in which sexual violence and violence in intimate relationships were experienced on a daily basis. Thus, it is possible to argue that exclusion and social control are two processes by which structural violence takes place.

As we have seen before, structural violence is defined as the processes underlying social inequities (Farmer et al., 2004; ScheperHughes \& Bourgois, 2004). It hinders some groups from fulfilling their basic needs (Ho, 2007) and causes suffering (Farmer et al., 2004). In this case, social exclusion has created precarious living conditions. Participants have addressed their financial difficulties, as well as their food and residential instability. In some situations, they have also been deprived of adequate care adapted to their situation, to the extent that these were denied or trivialized.

Structural violence is also characterized by how these three dimensions are related to each other (Galtung, 1990; Scheper-Hughes \& Bourgois, 2004). Scheper-Hughes and Bourgois suggest that structural violence is deliberately inflicted onto a population who is believed, through symbolic domination, to be less valuable (in this case, "value" is based on gender, delinquency or on behaviors that are seen as nonnormative femininity, sexual orientation, age, and social class). It appears that social exclusion and social control were experienced by the participants in coherence with the way this population is perceived. These young women were profiled because of their associated stigmas of poverty and marginalization and were crystallized into these situations, justifying to some extent the control to which they were subjected. These same markers can also give meaning to their experiences of exclusion, which were also motivated by these prejudices and the pressures stemming from heteronormative rape culture. Institutional violence has in turn reaffirmed the labeling process and reproduced prejudices.

For example, it can be argued that the way the participants were labeled as "bad girls" as they entered the child protective system may be due to tensions surrounding their gender role (Brown, 2011). In an environment where girls are socialized to be kind, caring, dedicated to others, and to suppress their anger (Brown, 2011; Lamb, 2002; Underwood, 2004), those who exhibit violent behavior or opposition expose themselves to face treatment that is focused on punishment, rather than on welfare (Brown, 2011). Once in the street, this labeling, combined with the presence of stigmas linked to poverty, marginality and non-normative femininity (tattoos, piercings or torn clothing) produces acts of profiling that justify the measures of control experienced by the participants. This supports the results of Campbell and Eid (2009) and Bellot et al. (2013) on the social profiling of people experiencing homelessness and criminalization.

Moreover, we can establish connections between the power relations related to gender and how these young women were treated by law enforcement. Considering that the culture of the police community is marked by misogyny and patriarchy (Franklin, 2007), it is possible that the behavior of police officers against young offenders was 
influenced by these values. Since activities related to street-based economy are mainly associated with young men (O'Grady \& Gaetz, 2009), one wonders if this could have influenced the attitude of police officers towards the participants of the study who were she-male gangsters (Young, 2009). Gender-based everyday violence was prominent in the lived experiences of the street-involved young women of this study.

ScheperHughes (2004) defines everyday violence as daily informal manifestations of violence that increase brutality within a microcommunity. It is possible that sexual violence occurred when participants tried to avoid social control, and that intimate partner violence reaffirmed the unequal power relations between men and women, contributing to the establishment of rape culture. The complex links between these three dimensions suggest that social exclusion and social control are two gendered processes by which structural violence has played a role in the lives of these young women.

Although the street appears to be an exit strategy for escaping control from the child protective system and for regaining control over their lives, a few participants were targeted with different stigmas associated with marginalization processes, poverty and crime. This seemed to "justify" their different experiences of exclusion that have kept them in life on the street and have generated poor living conditions. These same markers also contributed to police profiling, resulting in abusive identity checks and the issuing of tickets. Added to this, criminal activities are also seen as survival strategies in order to overcome social exclusion, such as drug trafficking, panhandling, theft or survival sex work. These activities led them to face even more control and have led some of them to enter the judicial system or face acts of police brutality. For most, social exclusion was reaffirmed when they had taken steps to get out of the street, like finding housing, completing requests for financial support, looking for a job, or seeking support from community organizations. Some participants withdrew from certain procedures, such as those related to employment, fearing exclusion because of their criminal record. All of these examples lead us to believe that social exclusion and control operate as a cycle that facilitate the male perpetration of intimate partner violence and sexual assault.

\section{Conclusion}

While this article focuses on structural violence, does not address the participants' agency, and provides a dark portrayal of their experiences, this article proposes a modest contribution to the first stages of reflection on recognizing structural violence as a social problem that produces and frames young women's homelessness. Understanding their experience through the prism of structural violence has laid a fresh look at the reality of this population. Although the concept of structural violence may appear large and difficult to translate empirically (Bernbeck, 2008; Stiles, 2011), operationalization put forward through the analysis of three dimensions - symbolic domination, institutional violence, and everyday violence - has helped structure the experience of the participants at microsocial and macrosocial levels, consistent with the paradigm of intersectionality.

While this article did not focus on PAR as a strategy to translate intersectionality into social practice, it addressed the intersection of oppressive systems, such as patriarchy (which also produces cisgenderism and heterosexism), classism, and ageism. While all of these are (re)produced and embodied in the participant's experiences, at the end of the day, participants fear acts of gendered-base violence, such as sexual assault and intimate partner violence. Gender inequality is also very salient in the way in which they experienced symbolic domination and institutional violence.

It is also possible to raise the hypothesis that exclusion and social control experienced by these women support a third process of structural violence: sexual exploitation. Stablein (2011) argues that relationships between young men and women in the street are shaped by the dynamics of sexual exploitation, demonstrating the ways in which sexual assault experienced by the participants are produced by the three dimensions of structural violence: symbolic, institutional and everyday violence. While further studies would be necessary in order to address structural violence among different populations of women, we still need to listen to street-involved young women if we want to understand their experiences and act together to help them overcome their challenges. The gendered aspects of structural violence experienced by the participants in this study also confirm the importance of addressing homelessness in a feminist perspective.

\section{Compliance with ethical standards}

This project is a part of Catherine Flynn Ph. D. research which is also part of a grant led by Professor Helene Berman. It is entitled Voices against violence and is funded by the CIHR (2011-2017). This Ph. D. candidate has also been awarded a Vanier Canada Graduate Scholarship, funded by the Social Sciences Research Council of Canada (2010-2013).

All procedures performed in studies involving human participants were in accordance with the ethical standards of University of Montreal and received ethical approval from its Arts and Sciences Faculty Ethical Board on November 11th 2011 (approval number: CERFAS-2011-12/ 85-P). Informed consent was obtained from all individual participants included in the study.

\section{Acknowledgements}

This project is part of a grant led by Professor Helene Berman, School of Nursing, Western University (ON) entitled "Voices Against Violence" and funded by the CIHR (2011-2017). This Ph.D. candidate had also been awarded a Vanier Canada Graduate Scholarship, funded by the Social Sciences Research Council of Canada (2010-2013).

\section{References}

Acoca, L. (1998). Outside/inside: The violation of American girls at home, on the streets and in the juvenile justice system. Crime \& Delinquency, 561-589.

Arnold, E. M., Kirk, R. S., Roberts, A. C., Griffith, D. P., Meadows, K., \& Julian, J. (2002). Treatment of incarcerated, sexually-abused adolescent females: An outcome study. Journal of Child Sexual Abuse, 12(1), 123-139.

Barnett, J. (2008). Peace and development: Towards a new synthesis. Journal of Peace Research, 45(1), 75-89.

Bastien Charlebois, J. (2011). Au-delà de la phobie de l'homo: quand le concept d'homophobie porte ombrage à la lutte contre l'hétérosexisme et l'hétéronormativité. Reflets: Revue d'intervention sociale et communautaire, 17(1), 112-149.

Belknap, J., \& Holsinger, K. (1998). An overview of delinquent girls: How theory and practice have failed and the need for innovative changes. Female offenders: Critical perspectives and effective interventions (pp. 31-64).

Bellot, C., Rivard, J., \& Greissler, É. (2010). L'intervention par les pairs: un outil pour soutenir la sortie de rue. Criminologie, 43(1), 171-198.

Bellot, C., Sylvestre, M., \& St-Jacques, B. (2013). Construire un problème social. Et pourquoi pas? Le cas de la judiciarisation de l'itinérance. Qu'est-ce qu'un problème social aujourd'hui-Repenser la non-conformité. Québec: Presses de l'Université du Québec207-228.

Bernbeck, R. (2008). Structural violence in archaeology. Archaeologies, 4(3), 390-413.

Bilge, S. (2015). Le blanchiment de l'intersectionnalité. Recherches Féministes, 28(2), 9-32.

Bill, L. (1998). The victimization and revictimization of female offenders: Prison administrators should be aware of ways in which security procedures perpetuate feelings of powerlessness among incarcerated women. Corrections Today, 60, 106-113.

Boivin, J.-F., Roy, É., Haley, N., \& du Fort, G. G. (2005). The health of street youth: A Canadian perspective. Canadian Journal of Public Health. Revue Canadienne de Sante Publique, 432-437.

Bourdieu, P. (1980). Le sens pratique. Ed. de minuit.

Brown, M. (2011). The sad, the mad and the bad: Co-existing discourses of girlhood. Communication présentée Child \& Youth Care Forum.

Buchwald, E., Fletcher, P. R., \& Roth, M. (2005). Transforming a rape culture. Minneapolis, MN: Milkweed Editions.

Butler, J. (2006). Trouble dans le genre. Pour un féminisme de la subversion. Population, (3), 347-349.

Campbell, C., \& Eid, P. (2009). La judiciarisation des personnes itinérantes à Montréal: un 
profilage social. Commission des droits de la personne et des droits de la jeunesse.

Chambers, S. A. (2007). An Incalculable Effect: Subversions of Heteronormativity. Political Studies, 55(3), 656-679.

Chen, X., Tyler, K. A., Whitbeck, L. B., \& Hoyt, D. R. (2004). Early sexual abuse, street adversity, and drug use among female homeless and runaway adolescents in the Midwest. Journal of Drug Issues, 34(1), 1-21.

Chettiar, J., Shannon, K., Wood, E., Zhang, R., \& Kerr, T. (2010). Survival sex work involvement among street-involved youth who use drugs in a Canadian setting. Journal of Public Health, 32(3), 322-327.

Collins, P. H. (2002). Black feminist thought: Knowledge, consciousness, and the politics of empowerment. Routledge.

Côté, P.-B. (2013). Les figures de l'intimité en situation de rue: une pluralité d'expériences chez les jeunes à Montréal.

Deliovsky, K. (2008). Normative white femininity: Race, gender and the politics of beauty. Atlantis: Critical Studies in Gender, Culture \& Social Justice, 33(1).

Dhillon, J. (2011). Social exclusion, gender, and access to education in Canada: Narrative accounts from girls on the street. Feminist Formations, 23(3), 110-134.

Dunkerley, S. (2017). Mothers matter: A feminist perspective on child welfare-involved women. Journal of Family Social Work, 20(3), 251-265.

Elliott, A. S. (2013). Meeting the health care needs of street-involved youth. Paediatrics \& Child Health, 18(6), 317-321.

Ensign, J., \& Panke, A. (2002). Barriers and bridges to care: Voices of homeless female adolescent youth in Seattle, Washington, USA. Journal of Advanced Nursing, 37(2), 166-172.

Farmer, P., Bourgois, P., ScheperHughes, N., Fassin, D., Green, L., Heggenhougen, H., \& Farmer, P. (2004). An anthropology of structural violence 1. Current Anthropology, 45(3), 305-325.

Feng, C., DeBeck, K., Kerr, T., Mathias, S., Montaner, J., \& Wood, E. (2013). Homelessness independently predicts injection drug use initiation among street-involved youth in a Canadian setting. Journal of Adolescent Health, 52(4), 499-501.

Ferguson, K. M. (2009). Exploring family environment characteristics and multiple abuse experiences among homeless youth. Journal of Interpersonal Violence, 24(11), 1875-1891.

Flicker, S., Maley, O., Ridgley, A., Biscope, S., Lombardo, C., \& Skinner, H. A. (2008). ePAR using technology and participatory action research to engage youth in health promotion. Action Research, 6(3), 285-303.

Flynn, C., \& Brassard, R. (2012). La maternité autochtone en contexte de violence structurelle: entre repères culturels, négociations et hégémonie. In S. dans Lapierre, \& D. Damant (Eds.). Regards critiques sur la maternité dans différents contextes sociaux (pp. 103-124). Québec: Presses de l'Université du Québec.

Flynn, C., Damant, D., Bernard, J., \& Lessard, G. (2016). Entre théorie de la paix et continuum de la violence: Réflexion autour du concept de la violence structurelle. Canadian Social Work Review/Revue canadienne de service social, 33(1), 45-64.

Flynn, C., Damant, D., \& Lessard, G. (2015). Le projet Dauphine: laisser la parole aux jeunes femmes de la rue et agir ensemble pour lutter contre la violence structurelle par l'entremise de la recherche-action participative1. Recherches féministes, 28(2), 53-79.

Foucault, M. (1975). Surveiller et punir, 1975. Paris: Gallimard.

Franklin, C. A. (2007). Male peer support and the police culture: Understanding the resistance and opposition of women in policing. Women \& Criminal Justice, 16(3), 1-25.

Galtung, J. (1969). Violence, peace, and peace research. Journal of Peace Research, 6(3), $167-191$.

Galtung, J. (1990). Cultural violence. Journal of Peace Research, 27(3), 291-305.

Gomez, R., Thompson, S. J., \& Barczyk, A. N. (2010). Factors associated with substance use among homeless young adults. Substance Abuse, 31(1), 24-34.

Grenier, A. M., \& Guberman, N. (2009). Creating and sustaining disadvantage: The relevance of a social exclusion framework. Health \& Social Care in the Community, 17(2), $116-124$.

Gutiérrez, G. (1973). In C. Inda, \& J. Eagleson (Eds.). A theology of liberation: History, politics, and salvation. Maryknoll, NY: Orbis Books.

Hadland, S. E., Marshall, B. D., Kerr, T., Qi, J., Montaner, J. S., \& Wood, E. (2012). Suicide and history of childhood trauma among street youth. Journal of Affective Disorders, 136(3), 377-380.

Hancock, A. M. (2007). Intersectionality as a normative and empirical paradigm. Politics \& Gender, 3(2), 248-254.

Harper, G. W., \& Carver, L. J. (1999). Out-of-the-mainstream youth as partners in collaborative research: exploring the benefits and challenges. Health Education \& Behavior, 26(2), 250-265.

Hayes, S., \& Carpenter, B. (2013). Social moralities and discursive constructions of female sex offenders. Sexualities, 16(1-2), 159-179.

Hlavka, H. R. (2014). Normalizing sexual violence: Young women account for harassment and abuse. Gender and Society, 28(3), 337-358.

Ho, K. (2007). Structural violence as a human rights violation. Essex Human Rights Review, $4(2), 1-17$.

James, S. E., Johnson, J., Raghavan, C., Lemos, T., Barakett, M., \& Woolis, D. (2003). The violent matrix: A study of structural, interpersonal, and intrapersonal violence among a sample of poor women. American Journal of Community Psychology, 31(1-2), $129-141$.

Kellington, S. (2000). 'Missing Voices': Mothers at Risk of Experiencing Apprehension in Child Welfare System in BC. Vancouver, BC Region: National Action Committee on the Status of Women.

Kidd, S. A., \& Carroll, M. R. (2007). Coping and suicidality among homeless youth.
Journal of Adolescence, 30(2), 283-296.

Kidd, S. A., Karabanow, J., Hughes, J., \& Frederick, T. (2013). Brief report: Youth pathways out of homelessness-Preliminary findings. Journal of Adolescence, 36(6), 1035-1037.

Lagraula-Fabre, M. (2005). La violence institutionnelle: une violence commise sur des personnes vulnérables par des personnes ayant autorité. Editions L'Harmattan.

Lamb, S. (2002). The secret lives of girls: What good girls really do-Sex play, aggression, and their guilt. Simon and Schuster.

L'Écuyer, R. (1990). Étapes de l'analyse de contenu: Modèle général. Méthodologie de L'analyse développementale de contenu: Méthode GPS et concept de soi (pp. 51-123). .

Loper, A. B., Institute of Law, Psychiatry \& Public Policy, University of Virginia, \& United States of America. (1999). Female juvenile delinquency: Risk factors and promising interventions. Juvenile justice fact sheet.

McCabe, K. M., Lansing, A. E., Garland, A. N. N., \& Hough, R. (2002). Gender differences in psychopathology, functional impairment, and familial risk factors among adjudicated delinquents. Journal of the American Academy of Child \& Adolescent Psychiatry, 41(7), 860-867.

MacDonald, J.-A. M., Gagnon, A. J., Mitchell, C., Meglio, G. D., Rennick, J. E., \& Cox, J. (2011). Include them and they will tell you: Learnings from a participatory process with youth. Qualitative Health Research, 21(8), 1127-1135.

Mayock, P., Corr, M.-L., \& O'Sullivan, E. (2013). Moving on, not out: When young people remain homeless. Journal of Youth Studies, 16(4), 441-459.

McHugh, T.-L. F., \& Kowalski, K. C. (2011). 'A new view of body image': A school-based participatory action research project with young Aboriginal women. Action Research, 9(3), 220-241.

McIntyre, A. (2000). Constructing meaning about violence, school, and community: Participatory action research with urban youth. The Urban Review, 32(2), 123-154.

Medrano, M. A., Desmond, D. P., Zule, W. A., \& Hatch, J. P. (1999). Histories of childhood trauma and the effects on risky HIV behaviors in a sample of women drug users. The American Journal of Drug and Alcohol Abuse, 25(4), 593-606.

Nehls, N., \& Sallmann, J. (2005). Women living with a history of physical and/or sexual abuse, substance use, and mental health problems. Qualitative Health Research, 15(3), 365-381.

O'Grady, B., \& Gaetz, S. (2004). Homelessness, gender and subsistence: The case of Toronto street youth. Journal of Youth Studies, 7(4), 397-416.

O'Grady, B., \& Gaetz, S. (2009). Street survival: A gendered analysis of youth homelessness in Toronto. Finding home: Policy options for addressing homelessness in Canada (pp. 7). .

Oliver, V. (2013). Healing home: Health and homelessness in the life stories of young women. University of Toronto Press.

Ordolis, E. (2007). A story of their own: Adolescent pregnancy and child welfare in Aboriginal communities. First Peoples Child \& Family Review, 3(4), 30-41.

Ozer, E. J., Ritterman, M. L., \& Wanis, M. G. (2010). Participatory action research (PAR) in middle school: Opportunities, constraints, and key processes. American Journal of Community Psychology, 46(1-2), 152-166.

Parsons, K. A. (2007). Structural violence and power. Peace Review, 19(2), 173-181.

Paugam, S. (1996). L'exclusion, l'état des savoirs. La découverte Paris.

Petrucka, P., Brooks, S., Smadu, G., McBeth, B., Bassendowski, S., Mackay, A., ... Fudger, S. (2014). At street level: Learnings, voices, experiences, and lifestyles of street involved youth.

Public Health Agency of Canada (2006). Street-Youth in Canada - Findings from Enhanced Surveillance of Canadian Street Youth, 1999-2003, Canada.

Rew, M. T.-S., \& ML Fitzgerald, L. (2001). Sexual abuse, alcohol and other drug use, and suicidal behaviors in homeless adolescents. Issues in Comprehensive Pediatric Nursing, 24(4), 225-240.

ScheperHughes, N. (2004). Dangerous and endangered youth: social structures and determinants of violence. Annals of the New York Academy of Sciences, 1036(1), 13-46.

Scheper-Hughes, N., \& Bourgois, P. I. (2004). Violence in war and peace. Blackwell Pub.

Shannon, K., Kerr, T., Allinott, S., Chettiar, J., Shoveller, J., \& Tyndall, M. W. (2008). Social and structural violence and power relations in mitigating HIV risk of drugusing women in survival sex work. Social Science \& Medicine, 66(4), 911-921.

Slater, J. M., Guthrie, B. J., \& Boyd, C. J. (2001). A feminist theoretical approach to understanding health of adolescent females. Journal of Adolescent Health, 28(6), $443-449$.

Stablein, T. (2011). Helping friends and the homeless milieu: Social capital and the utility of street peers. Journal of Contemporary Ethnography, 40(3), 290-317 (0891241610390365).

Stephen, D. E. (2000). Young women construct themselves: Social identity, self-concept and psychosocial well-being in homeless facilities. Journal of Youth Studies, 3(4), 445-460.

Stiles, C. E. (2011). Countering structural violence: Cultivating an experience of positive peace.

Tyler, K. A., Hoyt, D. R., Whitbeck, L. B., \& Cauce, A. M. (2001). The impact of childhood sexual abuse on later sexual victimization among runaway youth. Journal of Research on Adolescence, 11(2), 151-176.

Tyler, K. A., \& Melander, L. A. (2009). Discrepancies in reporting of physical and sexual abuse among homeless young adults. Journal of Child Sexual Abuse, 18(5), 513-531.

Tyler, K. A., Melander, L. A., \& Noel, H. (2009). Bidirectional partner violence among homeless young adults risk factors and outcomes. Journal of Interpersonal Violence, 24(6), 1014-1035.

Underwood, M. K. (2004). Girls and violence. Girls and aggression (pp. 239-247). Springer.

Valentine, G., \& Harris, C. (2014). Strivers vs skivers: Class prejudice and the 
demonisation of dependency in everyday life. Geoforum, 53, 84-92.

Walls, N. E., \& Bell, S. (2011). Correlates of engaging in survival sex among homeless youth and young adults. Journal of Sex Research, 48(5), 423-436.

Welch, C. L., Roberts-Lewis, A. C., \& Parker, S. (2009). Incorporating gender specific approaches for incarcerated female adolescents: Multilevel Risk Model for practice. Journal of Offender Rehabilitation, 48(1), 67-83.

Wingert, S., Higgitt, N., \& Ristock, J. (2005). Voices from the margins: Understanding street youth in Winnepeg. Canadian Journal of Urban Research, 14(1).

Young, T. (2009). Girls and gangs:'Shemale' gangsters in the UK? Youth Justice, 9(3), 224-238.

Catherine Flynn, Ph.D. is a member of the Feminist Anti-Violence Research Collective and TRAJETVI. Her research takes place within an intersectional feminist paradigm. Her studies, conducted with a participatory action research (PAR) methodology, are focused on homelessness, violence against women and intimate partner violence in terms of structural violence. She declares that she has no conflict of interest.

Dominique Damant, Ph.D.'s work on violence against women and her interest in intersectional feminism have led her to explore the intersection of sexism and racism. Recently, she has been interested in the subject of women with violent behaviors. She declares that she has no conflict of interest.
Simon Lapierre, Ph.D. is the director of the Feminist Anti-Violence Research Collective. His research projects, conducted in both Canada and the United Kingdom, propose a feminist and critical perspective on policies and practices in shelters and in the area of child and family social work, as well as on the social discourses that underpin these policies and practices. He declares that he has no conflict of interest.

Geneviève Lessard, Ph.D. is a member or the Interdisciplinary Research Center on Family Violence and Violence Against Women and TRAJETVI, she has extensive experience in the field of action research and intersectorial cooperation on domestic and family violence. She declares that she has no conflict of interest.

Charlotte Gagnon, M.s.s. is also a member of the Feminist Anti-Violence Research Collective. She declares that she has no conflict of interest.

Vanessa Couturier is a member and co-founder of the Feminist Anti-Violence Research Collective and works as a research assistant on different projects in the field of violence against women. She declares that she has no conflict of interest.

Pénélope Couturier is an undergratuate student in social work at University of Québec in Rimouski and works as a research assistant on different projects in the field of homelesness and violence against women. She declares that she has no conflict of interest. 